UC-700 and UC-000 Issued: August 1994

Prediction of Material Strength and Fracture of Glass Using the SPHINX Smooth Particle Hydrodynamics Code

David A. Mandell

Charles $A$. Wingate

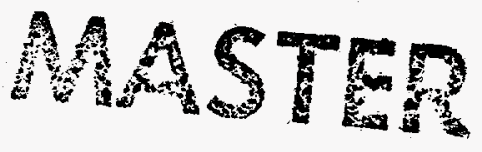




\section{DISCLAIMER}

This report was prepared as an account of work sponsored by an agency of the United States Government. Neither the United States Government nor any agency thereof, nor any of their employees, make any warranty, express or implied, or assumes any legal liability or responsibility for the accuracy, completeness, or usefulness of any information, apparatus, product, or process disclosed, or represents that its use would not infringe privately owned rights. Reference herein to any specific commercial product, process, or service by trade name, trademark, manufacturer, or otherwise does not necessarily constitute or imply its endorsement, recommendation, or favoring by the United States Government or any agency thereof. The views and opinions of authors expressed herein do not necessarily state or reflect those of the United States Government or any agency thereof. 


\section{DISCLAIMER}

Portions of this document may be illegible in electronic image products. Images are produced from the best available original document. 


\title{
PREDICTION OF MATERIAL STRENGTH AND FRACTURE OF GLASS USING THE SPHINX SMOOTH PARTICLE HYDRODYNAMICS CODE
}

\author{
by \\ David A. Mandell and Charles A. Wingate
}

\begin{abstract}
The design of many military devices involves numerical predictions of the material strength and fracture of brittle materials. The materials of interest include ceramics, that are used in armor packages; glass that is used in truck and jeep windshields and in helicopters; and rock and concrete that are used in underground bunkers. As part of a program to develop advanced hydrocode design tools, we have implemented a brittle fracture model for glass into the SPHINX smooth particle hydrodynamics code. We have evaluated this model and the code by predicting data from onedimensional flyer plate impacts into glass, and data from tungsten rods impacting glass. Since fractured glass properties, which are needed in the model, are not available, we did sensitivity studies of these properties, as well as sensitivity studies to determine the number of particles needed in the calculations. The numerical results are in good agreement with the data.
\end{abstract}

\section{INTRODUCTION}

The numerical prediction of ceramic, including glass and rocks, material strength, and fracture is important in the design of a number of military and commercial products. The predictions are important in armor/anti-armor design, including the penetration and fracture of glass windshields; in the design of devices to defeat hardened, underground targets; in oil well recovery work in order to predict the fracture of rock; and in safety analyses for engines using ceramic blades where the effect of debris entering the engine needs to be predicted.

In the current work we use the SPHINX smooth particle hydrodynamics code (Stellingwerf and Wingate, 1993; Wingate and Stellingwerf, 1994), described below, to predict data from one-dimensional experiments in which an aluminum flyer plate impacted a glass target (Raiser et al., 1994; Grady and Wise, 1993), and two-dimensional experiments in which a tungsten rod impacted glass, backed by mild steel (Anderson et al., 
1993). In the flyer plate experiments, a VISAR (laser velocity interferometer system) was used to measure the velocity as a function of time at the rear of the glass plate. In the two-dimensional experiments, a series of experiments was conducted, and the tip and tail positions of the tungsten rod were obtained as a function of time.

As has been noted previously (Mandell, 1993), the fracture model used for predictions of impacts into ceramics is critical. In addition, a fracture model that is adequate to predict one-dimensional experiments may give very poor results when predicting multi-dimensional experiments. In the current work we use the glass fracture model developed by Cagnoux (Cagnoux, 1985) and extended by Glenn and his co-workers (Glenn et al., 1990). This model is described below.

\section{SPHINX MODELS}

Smooth Particle Hydrodynamics (SPH) is a relatively new technique for doing hydrodynamics calculations. It is a gridless, Lagrangian method in which fluid elements are represented by mass points that move according to the fluid equations of motion. Each particle carries local values of density, temperature, pressure, and other fluid parameters. Interpolation is used to find values of physical quantities between the particles.

The key feature of SPH is that it is gridless and thus does not have the mesh tangling problems of typical Lagrangian codes. Since SPH is Lagrangian, it does not have the problems with advection that typical Eulerian codes have. Also SPH only needs particles where the material is and thus does not have to zone up huge volumes of space.

The Los Alamos SPHINX code is the SPH code used in this work. The current version of the code has many equations of state including perfect gas, Grueneissen, and SESAME (Holian, 1984). It runs in 1D, 2D, 3D Cartesian coordinates, 2D cylindrically symmetric and 1D spherically symmetric (all in the same code) coordinate systems. Elastic perfectly plastic, Johnson-Cook (Johnson and Cook, 1983) and Steinberg-Guinan (Steinberg et al., 1980) strength of material models are in the code. Two high explosive burn models are available. Fracture modeling with SPHINX is an area of ongoing research. Fracture models currently available include a simple void fracture model, a Grady-Kipp ( Grady and Kipp, 1980) type model and most recently the Cagnoux-Glenn brittle fracture model, which was implemented for this project and used to predict the glass damage in the work discussed in this report. The code has an option to solve the continuity equation independent of the normal SPH equations. It uses Runge Kutta to do the time stepping.

The glass model developed by Cagnoux (Cagnoux, 1985), and extended by Glenn and his co-workers (Glenn et al., 1990) was implemented into SPHINX. This model consists of an ordinary differential equation for the 
glass damage, and a prescription for the damaged glass strength properties and an equation of state. The model is discussed below.

A scalar damage variable, $D$, is calculated from the following equation

$$
\frac{d D}{d t}=\frac{\tau}{B(1-D)^{b \tau}}
$$

where $\tau$ is the maximum principal tensile stress, and $\mathrm{B}$ and $\mathrm{b}$ are material constants. The damage is zero for intact glass and one for fully damaged glass. Damage is accumulated only if $\tau$ is greater than a threshold value, $\tau_{0}$. The values of $B$ and $b$ given by Cagnoux (Cagnoux, 1985) were used in the calculations shown in this report: $B=7.010^{-5} \mathrm{kbar}$-seconds and $b=0.7$ kbar $^{-1}$.

Once the damage is calculated, it is important to degrade the glass material strength and equation of state (EOS) in an appropriate manner. A number of methods have been used, but in the Cagnoux-Glenn model, the bulk modulus, $\mathrm{K}$; shear modulus, G; and yield strength, $\mathrm{Y}$, are calculated as linear functions between the intact and fractured values

$$
f=f_{0}(1-D)+f_{0} f_{R} D,
$$

where $f$ is $K, G$, or $Y$. The subscript o refers to intact glass properties and the subscript $R$ refers to the ratio of the fractured glass property to the intact glass property. The EOS is

$$
\frac{d p}{d v}=-K v,
$$

where $p$ is the pressure and $v$ is the glass specific volume. It should be noted that once damage starts to accumulate, the slope of the EOS equation, $K$, changes, resulting in increased glass pressure. This provides the dilatation (bulking) seen in experiments. A schematic of the glass EOS is shown in Fig. 1 . The energy term added to the pressure EOS equation was not used in our work (Glenn et al., 1990). This EOS was used for the glass in all of the calculations shown in this report. 


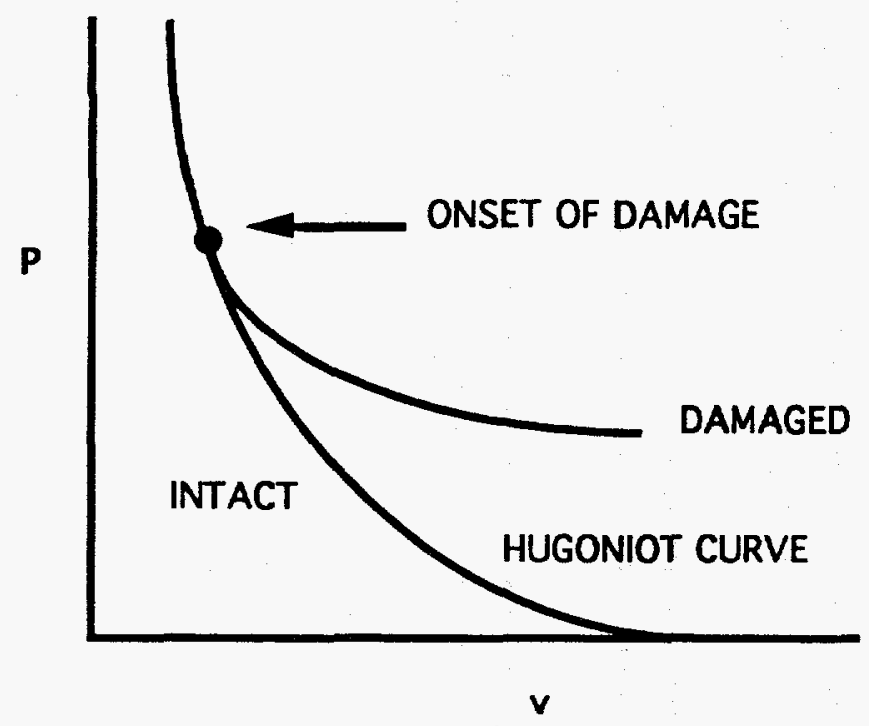

Fig. 1. Intact and fractured glass pressure

We varied the values of $K_{R}, Y_{R}$, and $G_{R}$ until we matched one experiment, since the fractured glass properties have not been measured, to our knowledge. We then used these values to predict other experiments. The results of the sensitivity study done on the fractured glass properties are presented below.

SPHINX uses cgs units (grams, centimeters, seconds, and degrees Kelvin). Some constants in this report are given in kbar and microseconds because of their use in armor work.

\section{ONE-DIMENSIONAL FLYER PLATES}

As indicated above, data from one-dimensional flyer plate experiments provide a necessary, but not sufficient, test of a brittle fracture model and of the implementation of the model into a hydrocode. Four aluminosilicate glass flyer plate impact experiments were conducted at the Sandia National Laboratories (Raiser et al., 1994; Grady and Wise, 1993). In two experiments the 6061-T6 aluminum flyer plates had a velocity of approximately 0.96 $\mathrm{km} / \mathrm{sec}$, and in the other two experiments the velocity was about $0.45 \mathrm{~km} / \mathrm{sec}$. In each set of experiments, one experiment was conducted with a roughened glass surface and the other with a smooth surface. Hydrocodes cannot predict the effect of the surface, so we predicted the experiments with smooth glass surfaces. A schematic of the geometry is shown in Fig. 2. 


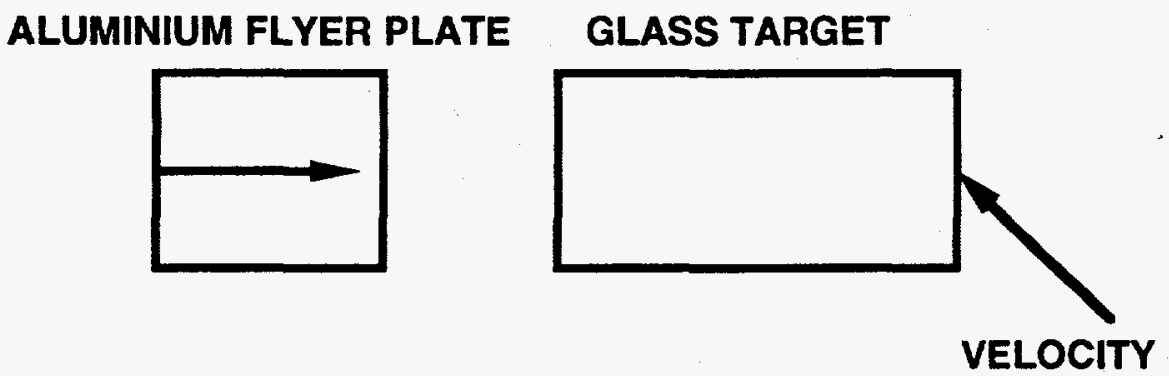

Figure 2. Schematic for the 1-D Glass Flyer Plate Predictions.

The experiment at the higher velocity apparently had a sufficiently large compressive strength that the glass spall strength, $\tau_{0}$, went to zero (Raiser et al., 1994). For the two lower velocity experiments, spall strengths of 34.9 and 33.5 kbar were reported (Grady and Wise, 1993). The SPHINX predictions therefore used a spall strength of zero for the higher velocity prediction and a spall strength of $34 \mathrm{kbar}$ for the lower velocity one.

The aluminum flyer plate had a length of $3.60 \mathrm{~mm}$, and the glass target had a length of $5.0 \mathrm{~mm}$. An elastic plastic material strength model was used for each material. The Grueneissen $\left(U_{s}-U_{p}\right)$ equation of state (EOS) was used for the aluminum, and the Glenn EOS was used for the glass. The aluminum properties used in the calculations are given in Table 1, the glass properties are given in Table 2, and a SPHINX sample input file is given in Appendix A. 


\begin{tabular}{|l|l|}
\hline VARIABLE & VALUE \\
\hline & \\
\hline Density $\left(\mathrm{gm} / \mathrm{cm}^{3}\right)$ & 2.7128445 \\
\hline Sound Speed $(\mathrm{cm} /$ microsecond) & 0.538 \\
\hline EOS Slope & 1.55 \\
\hline Shear Modulus (Kbar) & 265.0 \\
\hline Yield Stress (Kbar) & 2.75 \\
\hline
\end{tabular}

Table 1. 6061-T6 aluminum properties.

\begin{tabular}{|l|l|}
\hline VARIABLE & VALUE \\
\hline & \\
\hline Density (gm/ $\mathrm{cm}^{3}$ ) & 2.60 \\
\hline Shear Modulus (Kbar) & 333.0 \\
\hline Yield Stress (Kbar) & 100.0 \\
\hline Bulk Modulus (Kbar) & 417.0 \\
\hline $\begin{array}{l}\text { YR (Ratio of fractured yield stress to } \\
\text { intact yield stress) }\end{array}$ & 0.1 \\
\hline $\begin{array}{l}\text { GR (Ratio of fractured shear modulus } \\
\text { to intact shear modulus) }\end{array}$ & 0.333 \\
\hline $\begin{array}{l}\text { KR (Ratio of fractured bulk modulus } \\
\text { to intact bulk modulus) }\end{array}$ & 0.333 \\
\hline
\end{tabular}

Table 2. Properties of aluminosilicate glass used in the SPHINX calculations.

The SPHINX predictions of the glass free surface velocity for the two glass flyer plate experiments are shown in Figure 3. One thousand particles were used in these calculations, which are more than sufficient for a converged solution in one-dimension. Calculations were also made with 100 and 2000 particles for the lower velocity case. The calculation with 100 particles was a little different from the one with 1000 particles. The calculations with 1000 and 2000 particles were virtually identical. The elastic plastic material strength model was used for both materials. 


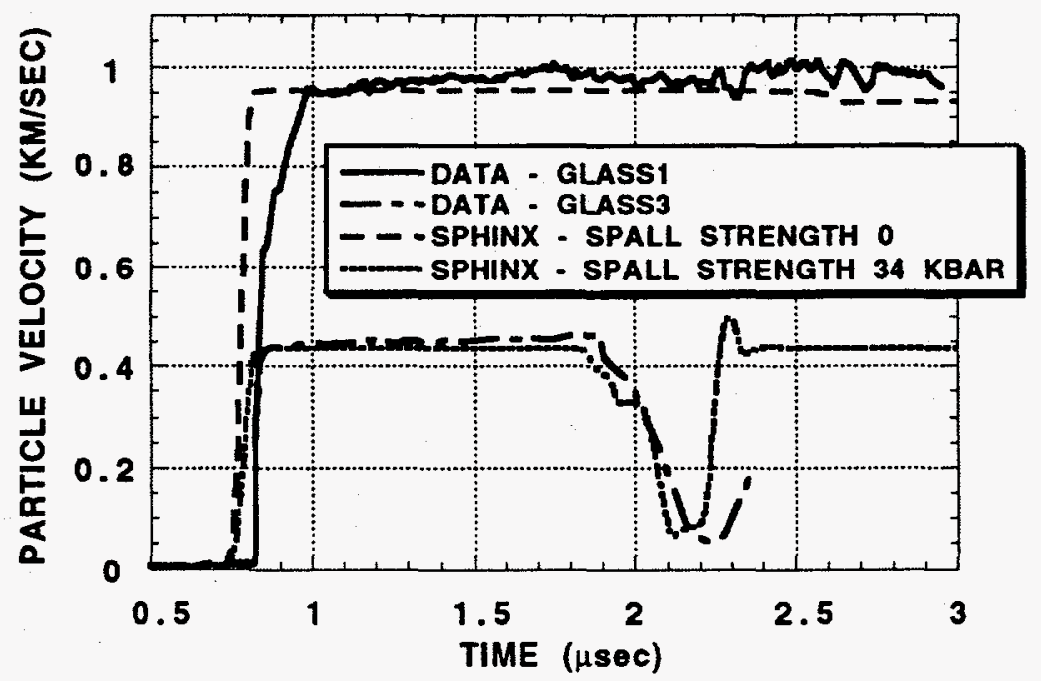

Fig. 3. Glass Free Surface Velocity.

It is seen from the above figure that the predictions are in reasonably good agreement with the data. If the same spall strength is used for both experiments, either 0 or $34 \mathrm{kbar}$, only one of the experiments can be predicted well.

\section{TUNGSTEN RODS IMPACTING STEEL}

As a base case before doing the glass impact experiments, Anderson and his co-workers (Anderson et al., 1993) did experiments in which a tungsten rod impacted steel. Since the main object of the present work is to evaluate brittle material strength and fracture models using the smooth particle hydrodynamics method, SPHINX predictions of data for impacts into metal were done to verify that the hydrocode input parameters and number of particles were correct.

These base case experiments consist of a blunt nosed tungsten alloy cylinder impacting armor steel as shown in Fig. 4. The rod had a radius of $0.20 \mathrm{~cm}$ and a length of $5.0 \mathrm{~cm}$. The steel radius was $2.0 \mathrm{~cm}$, and the length was $2.9 \mathrm{~cm}$. 
TUNGSTEN ALLOY

ROD

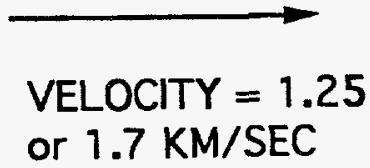

\section{ARMOR}

STEEL

Fig. 4. Geometry for Tungsten Rod Impacting Steel.

Figure 5 shows the initial SPHINX geometry on the plane of symmetry, and Fig. 6 shows the corresponding geometry at 60 microseconds. In order to reduce the computer resources used, a variable SPH particle spacing was used, with a spacing of 1.1 between adjacent particles. This effect can be seen in Figures 5 and 6 where there is a fine zoning in the most important region of the problem near the axis of symmetry where it is needed and coarse zoning at the edges.

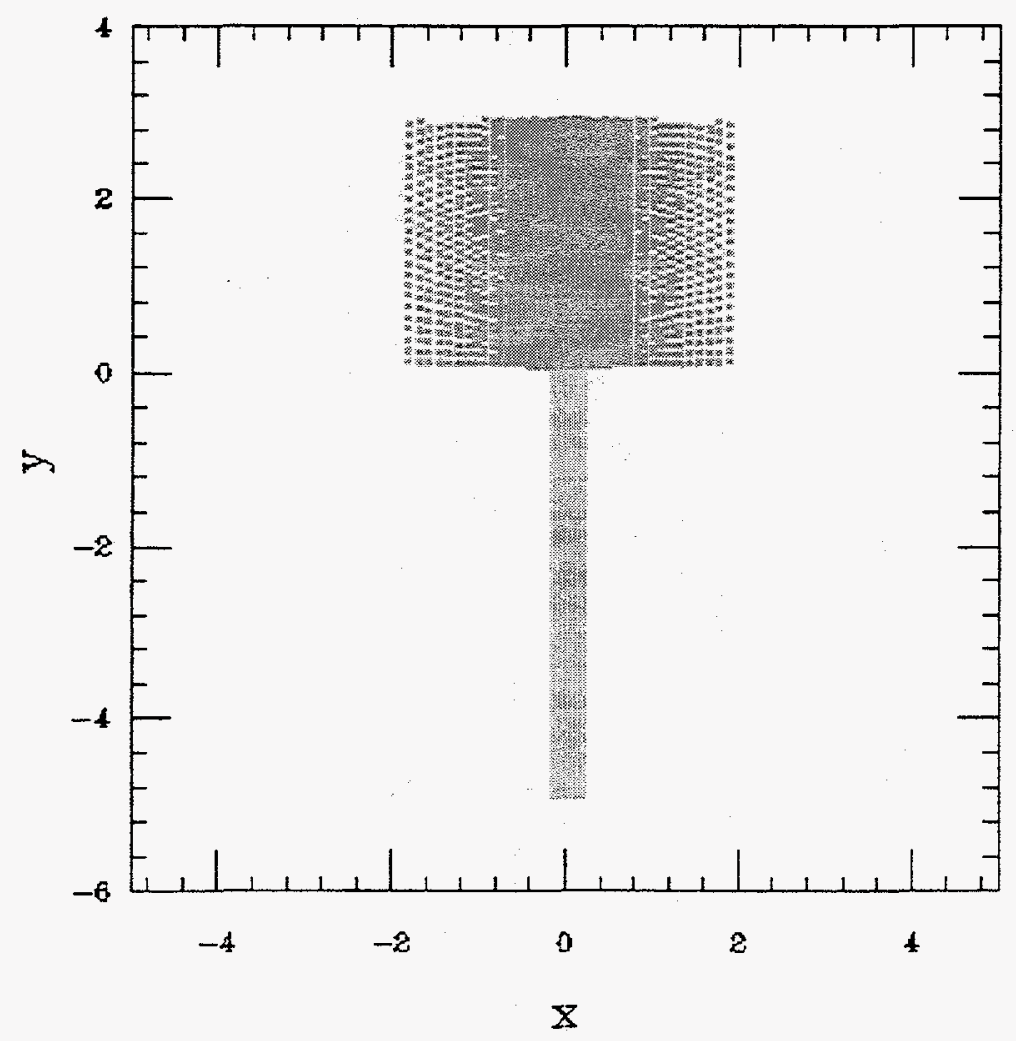

Fig. 5. SPHINX 2-D Axisymmetric Geometry for Tungsten Rod Penetrating Steel - Time $=0.0$. 


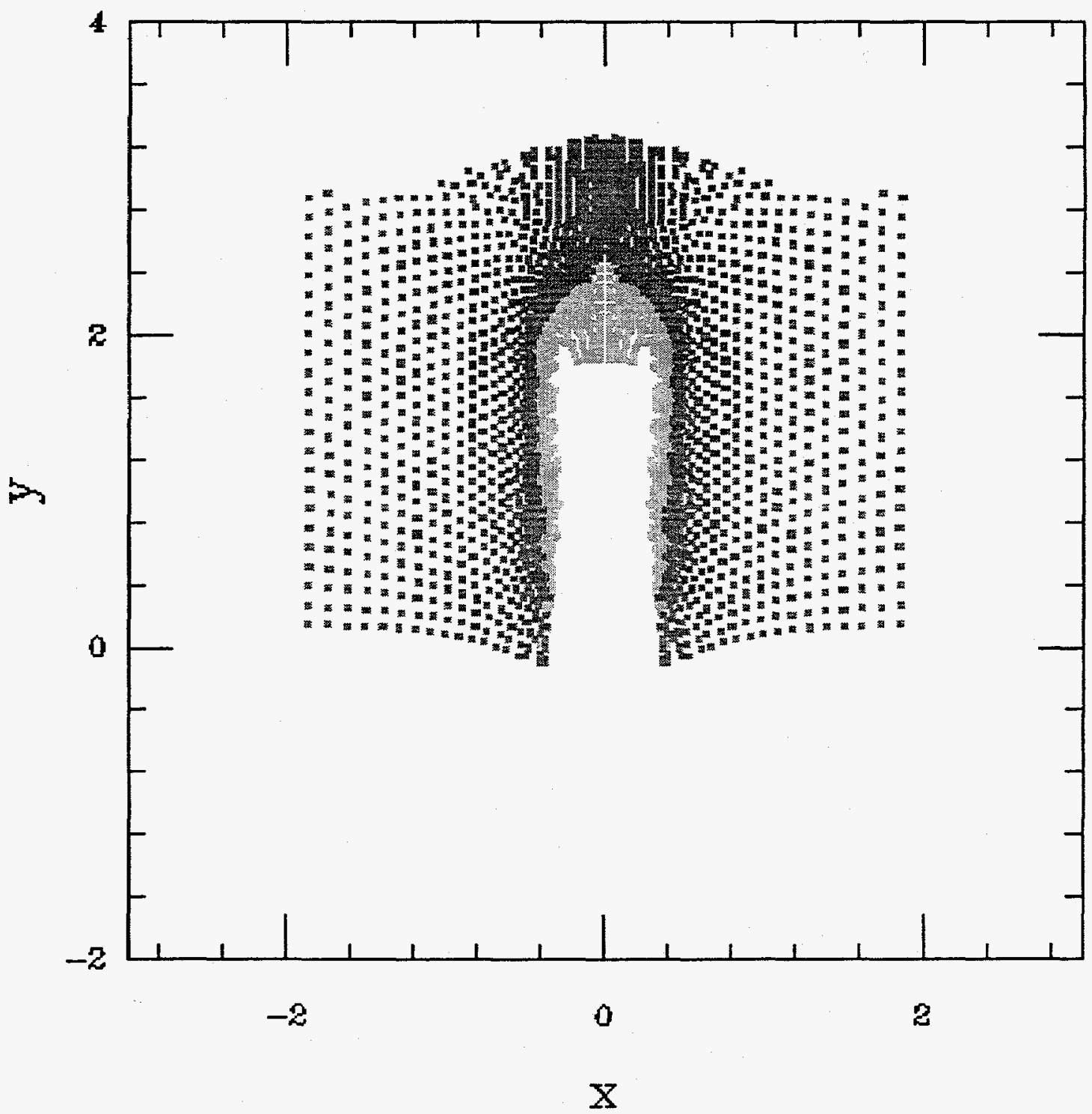

Fig. 6. Penetration of a Tungsten Rod Into Steel - Time $=60$ Microseconds. 
The computational model consisted of the elastic plastic strength model in the rod and the Johnson-Cook model (Johnson and Cook, 1983) in the steel. No fracture model was used in these predictions. The tungsten properties used in the calculations are given in Table 3, and the steel properties are given in Table 4. The Los Alamos SESAME tabular equations of state were used for both the tungsten and the steel (Holian, 1984). The SPHINX input file for run steel04 is given in Appendix B.

\begin{tabular}{|l|l|}
\hline VARIABLE & VALUE \\
\hline & \\
\hline Density $\left(\mathrm{g}^{\mathrm{c}} \mathrm{cm}^{3}\right)$ & 17.75 \\
\hline Shear Modulus (Kbar) & 1388.0 \\
\hline Yield Stress (Kbar) & 13.0 \\
\hline
\end{tabular}

Table 3. Tungsten Properties.

\begin{tabular}{|l|l|}
\hline VARIABLE & VALUE \\
\hline & \\
\hline Density (gm/cm 3 ) & 7.81 \\
\hline Shear Modulus (Kbar) & 776.0 \\
\hline Yield Stress (Kbar) & 11.89 \\
\hline Johnson Cook A (Kbar) & 11.89 \\
\hline Johnson Cook B (Kbar) & 7.65 \\
\hline Johnson Cook n & 0.26 \\
\hline Johnson Cook C & 0.014 \\
\hline Johnson Cook m & 1.03 \\
\hline Johnson Cook Melt Temperature ( $\left.{ }^{\circ} \mathrm{K}\right)$ & 1793.0 \\
\hline
\end{tabular}

Table 4. Steel Properties

Figure 7 shows the rod tip and tail positions as a function of time for the data and predictions of the tungsten rod penetrating into armor steel. As can be seen, the SPHINX predictions are in good agreement with the data. Predictions are shown for 370 and 1280 SPH particles. After 50 microseconds; only a small difference exists between the two predictions indicating that particle ("mesh") convergence has been achieved. The quantities in parentheses in the figure legends are the computational run designations (e.g. steel04). 


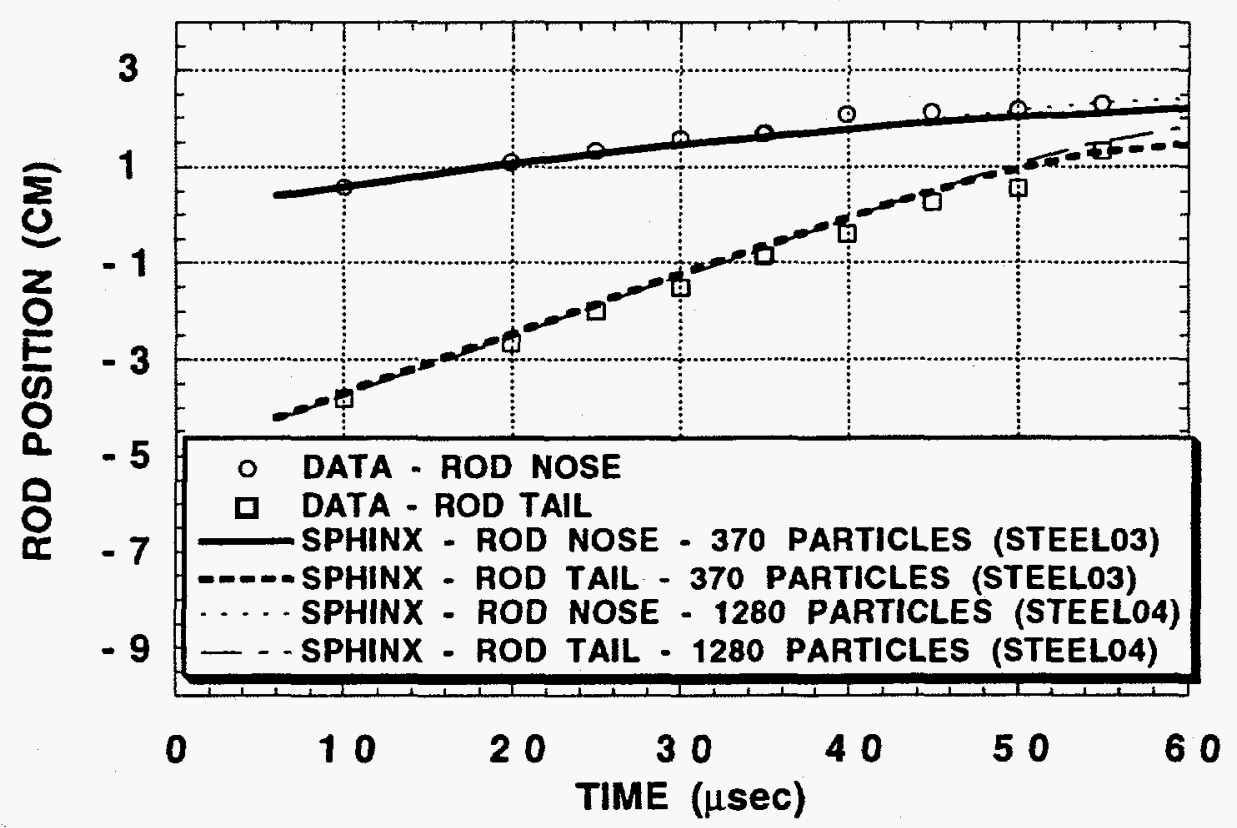

Figure 7. Rod Position - Tungsten Impacting Glass.

It is of interest to compare the computer times between runs with different numbers of particles. All of the calculations done in this work were done on a Cray Y-MP. The CPU times used for the two steel runs are shown in Table 5.

\begin{tabular}{|l|l|}
\hline NUMBER OF PARTICLES & CPU TIME (MINUTES) \\
\hline & \\
\hline 370 & 2.48 \\
\hline 1280 & 25.3 \\
\hline
\end{tabular}

Table 5. Cray Y-MP CPU time used in the steel penetration calculations.

With this agreement for the penetration into a metal, the predictions into glass can be made knowing that discrepancies between the predictions and the data are due to the material strength and fracture model for the glass.

\section{TUNGSTEN RODS IMPACTING GLASS}

The goal of this work is provide a hydrocode tool for use in armor/antiarmor design, especially for design involving brittle material strength and fracture. The materials of interest are ceramics, such as alumina and silicon carbide; and glass, which is used in truck and jeep windshields, and in helicopters. A brittle material strength and fracture model can only be qualified for design if it can predict multi-dimensional problems. Therefore, as part of this qualification effort, we predicted two-dimensional impact 
experiments into soda lime glass (Anderson et al., 1993). Figure 8 shows a schematic of the geometry, which consists of a tungsten alloy rod impacting glass, backed by mild steel.

\section{TUNGSTEN ALLOY}

\section{WINDOW GLASS}

MILD

STEEL

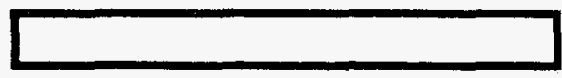

\section{VELOCITY $=1.25$ or 1.7}

$\mathrm{KM} / \mathrm{SEC}$

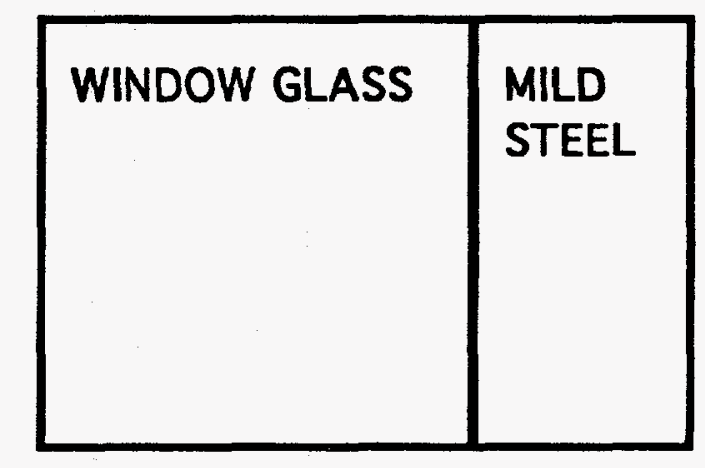

Fig. 8. Geometry for Tungsten Rod Impacting Glass.

The dimensions and properties used for the tungsten, glass, and mild steel for these calculations are shown in Tables 5-7. The input file for run g50 is given in Appendix C. The Grueneissen EOS and the elastic plastic strength model were used for the tungsten and mild steel. In these calculations, only the glass was allowed to fracture.

\begin{tabular}{|l|l|}
\hline VARIABLE & VALUE \\
\hline & \\
\hline Diameter $(\mathrm{cm})$ & 0.58 \\
\hline Length $(\mathrm{cm})$ & 7.25 \\
\hline Density $\left(\mathrm{gm} / \mathrm{cm}^{3}\right)$ & 17.75 \\
\hline Yield stress $(\mathrm{kbar})$ & 13.0 \\
\hline Shear Modulus $(\mathrm{kbar})$ & 1388.0 \\
\hline Sound speed $(\mathrm{cm} / \mu \mathrm{sec})$ & 0.399 \\
\hline EOS slope, S & 1.237 \\
\hline
\end{tabular}

Table 5. Tungsten rod dimensions and properties for the glass impacts.

\begin{tabular}{|l|l|}
\hline VARIABLE & VALUE \\
\hline & \\
\hline Diameter $(\mathrm{cm})$ & 15.0 \\
\hline Length $(\mathrm{cm})$ & 20.0 \\
\hline Density $\left(\mathrm{gm} / \mathrm{cm}^{3}\right)$ & 2.5 \\
\hline Intact yield stress $(\mathrm{kbar})$ & 10.0 \\
\hline Intact shear modulus $(\mathrm{kbar})$ & 333.0 \\
\hline Intact bulk modulus $(\mathrm{kbar})$ & 555.0 \\
\hline Damage threshold, $\tau_{0}(\mathrm{kbar})$ & 0.9 \\
\hline
\end{tabular}

Table 6. Glass dimensions and properties for the glass impacts. 


\begin{tabular}{|l|l|}
\hline VARIABLE & VALUE \\
\hline & \\
\hline Diameter $(\mathrm{cm})$ & 15.0 \\
\hline Length $(\mathrm{cm})$ & 10.0 \\
\hline Density $\left(\mathrm{gm} / \mathrm{cm}^{3}\right)$ & 7.85 \\
\hline Shear modulus $(\mathrm{kbar})$ & 775.0 \\
\hline Yield stress $(\mathrm{kbar})$ & 7.924 \\
\hline Sound Speed $(\mathrm{cm} / \mu \mathrm{sec})$ & 0.596 \\
\hline EOS slope, $\mathrm{S}$ & 1.5176 \\
\hline
\end{tabular}

Table 7. Mild steel dimensions and properties for the glass impacts.

Figures 9 and 10 show the SPHINX plane of symmetry geometry at time zero. A variable particle spacing of 1.1 was again used, as can be seen in the figures. Figure 11 shows the mesh at 325 microseconds. The tungsten rod is almost completely eroded by this time.

The glass model used in this work, the Cagnoux-Glenn model, requires a knowledge of both the intact and the fractured glass properties - bulk modulus, $K$; shear modulus, G; and yield stress, Y. Intact glass properties are reasonably well known, but the properties of the fractured glass are not available. Therefore we have varied the ratios of the fractured to the intact properties, $K_{R}, G_{R}$, and $Y_{R}$, to match the experiments in which the rod velocity was $1.25 \mathrm{~km} / \mathrm{sec}$. We then ran the higher velocity experiment, which was at $1.70 \mathrm{~km} / \mathrm{sec}$, to determine if the fractured glass properties were valid for conditions other than those for which they were determined.

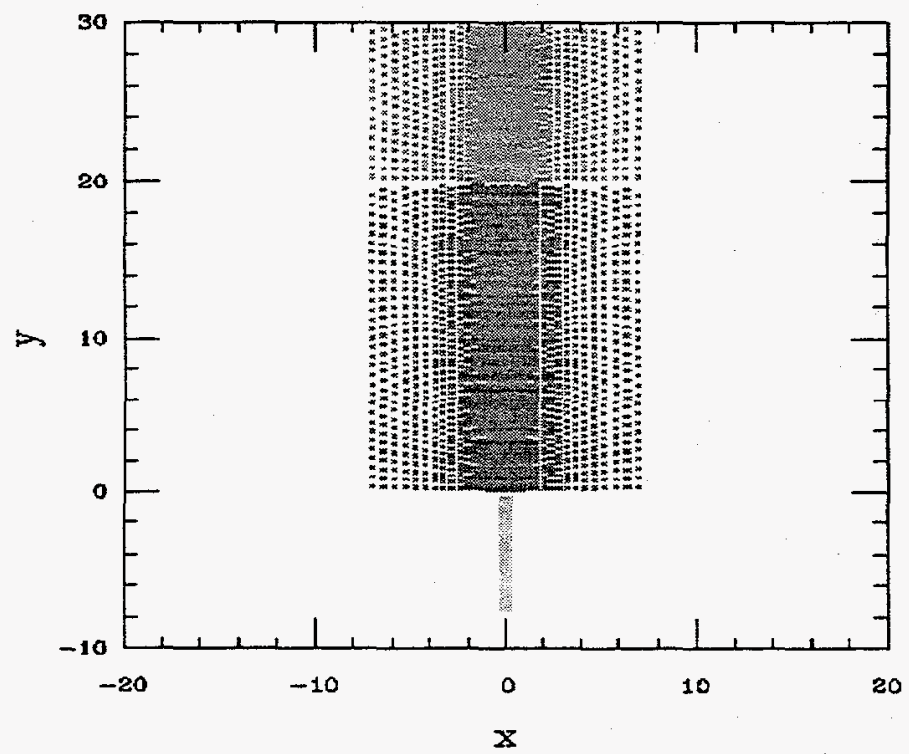

Fig. 9. Initial SPHINX Geometry for a Tungsten Rod Impacting Glass - Time $=0.0$. 


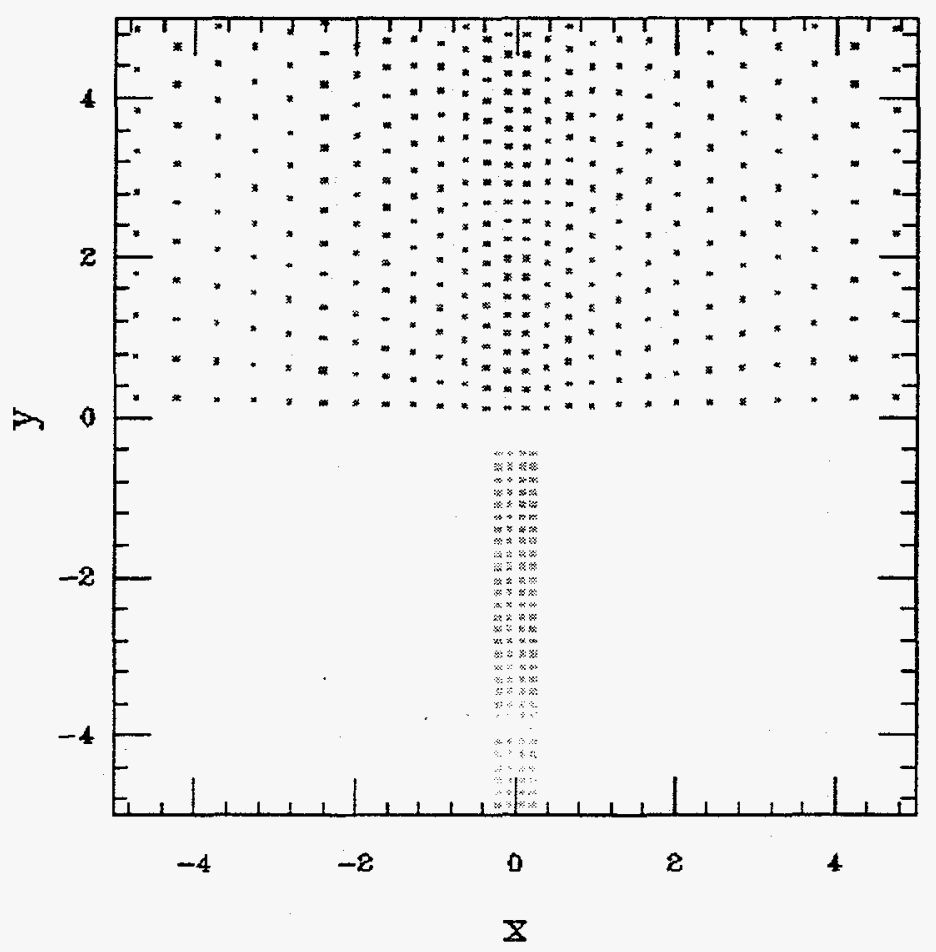

Fig. 10. Initial Geometry for a Tungsten Rod Impacting Glass Showing Individual SPH Particles - Time $=0.0$.

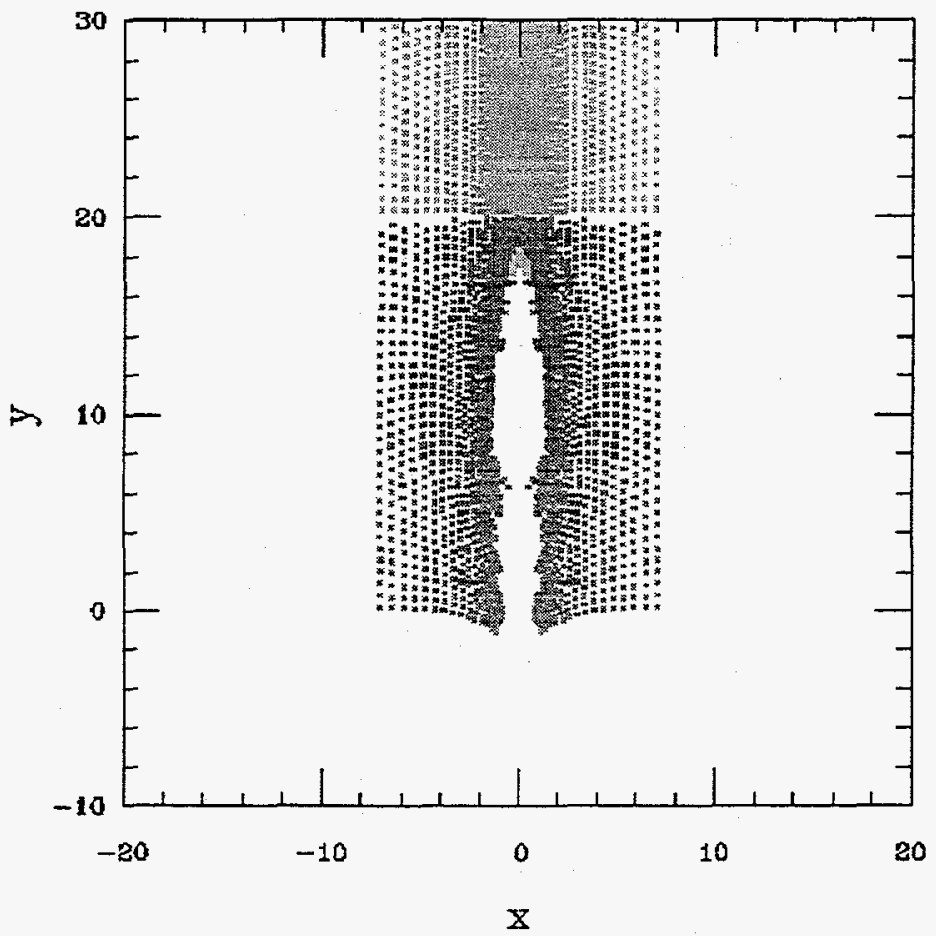

Fig. 11. Final Geometry for a Tungsten Rod Penetrating Glass - Time $=325$ Microseconds. 
Figure 12 shows the tungsten rod nose position for the experiments in which the rod was at an initial velocity of $1.25 \mathrm{~km} / \mathrm{sec}$. This figure shows the data, a calculation without damage, and a series of calculations with damage in which the ratio of the fractured yield stress to the intact yield stress was varied (YR). For $\mathrm{Yr}=1.0$, only the bulk modulus and shear modulus are decreased after the glass is fractured. Several conclusions can be reached from these results. Numerical predictions of glass impacts are greatly in error when no fracture of the glass is allowed. In addition many models let the glass strength go to zero once a cell completely fractures $(\mathrm{D}=1.0)$. The model used in this work shows that some glass strength remains after fracture. The results are sensitive to the value of $Y R$, but in all cases the predictions are much better using any nonzero value of $\mathrm{YR}$ than assuming that no fracture occurs.

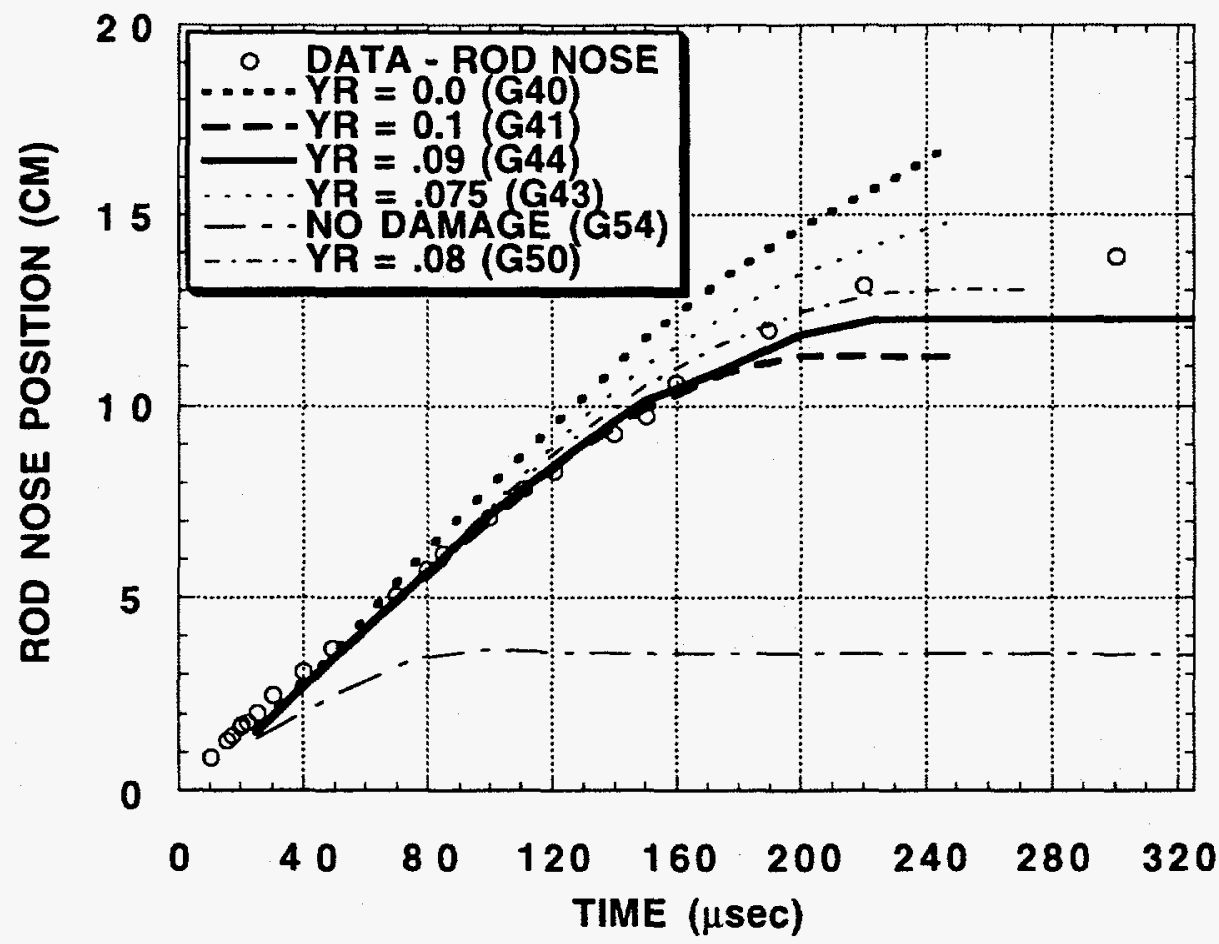

Fig. 12. Predictions of Tungsten Rods Penetrating Glass - Effect of Fractured Glass Yield Stress.

Figure 13 shows the effect of the number of SPH particles used in the calculation. A balance should be achieved between having enough particles so that the answers are converged and not wasting computer resources by using too many particles. A nominal number of particles is input to SPHINX, but an internal algorithm determines the actual number of particles used. The figure shows that 804 particles is insufficient, but the results for 1392 and 
2286 particles are very close. Unless otherwise noted, the calculations shown in this report were done using $1392 \mathrm{SPH}$ particles.

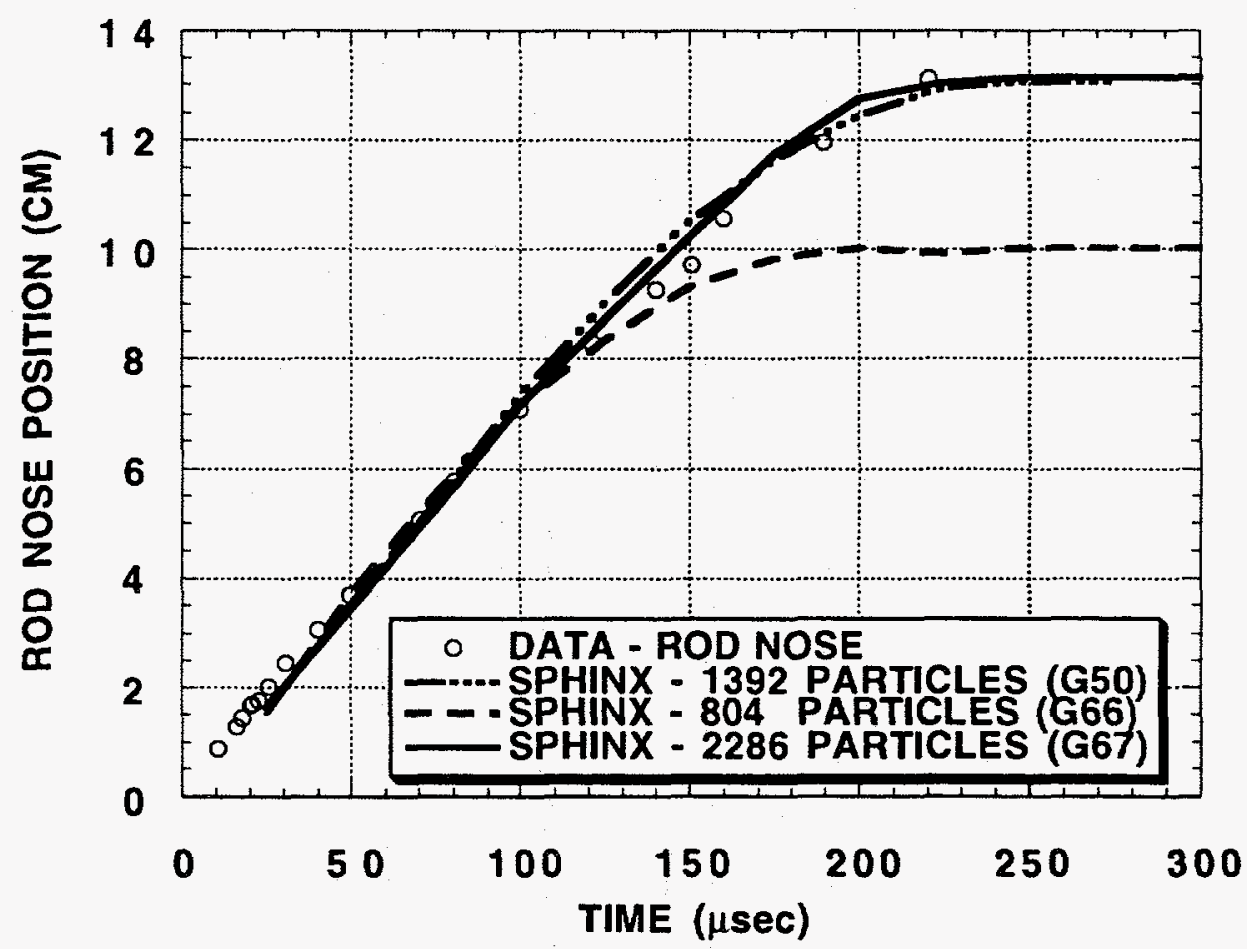

Fig. 13. Predictions of Tungsten Rods Penetrating Glass at $1.25 \mathrm{Km} / \mathrm{Sec}$. Effect of the Number of Particles.

Figure 14 shows the results of varying the fractured glass shear modulus. The figure shows that varying the ratio of the fractured glass shear modulus to the intact value, GR, over a wide range had a relatively small effect on the rod tip position results. A value of 0.333 was used for GR in the majority of the calculations. 


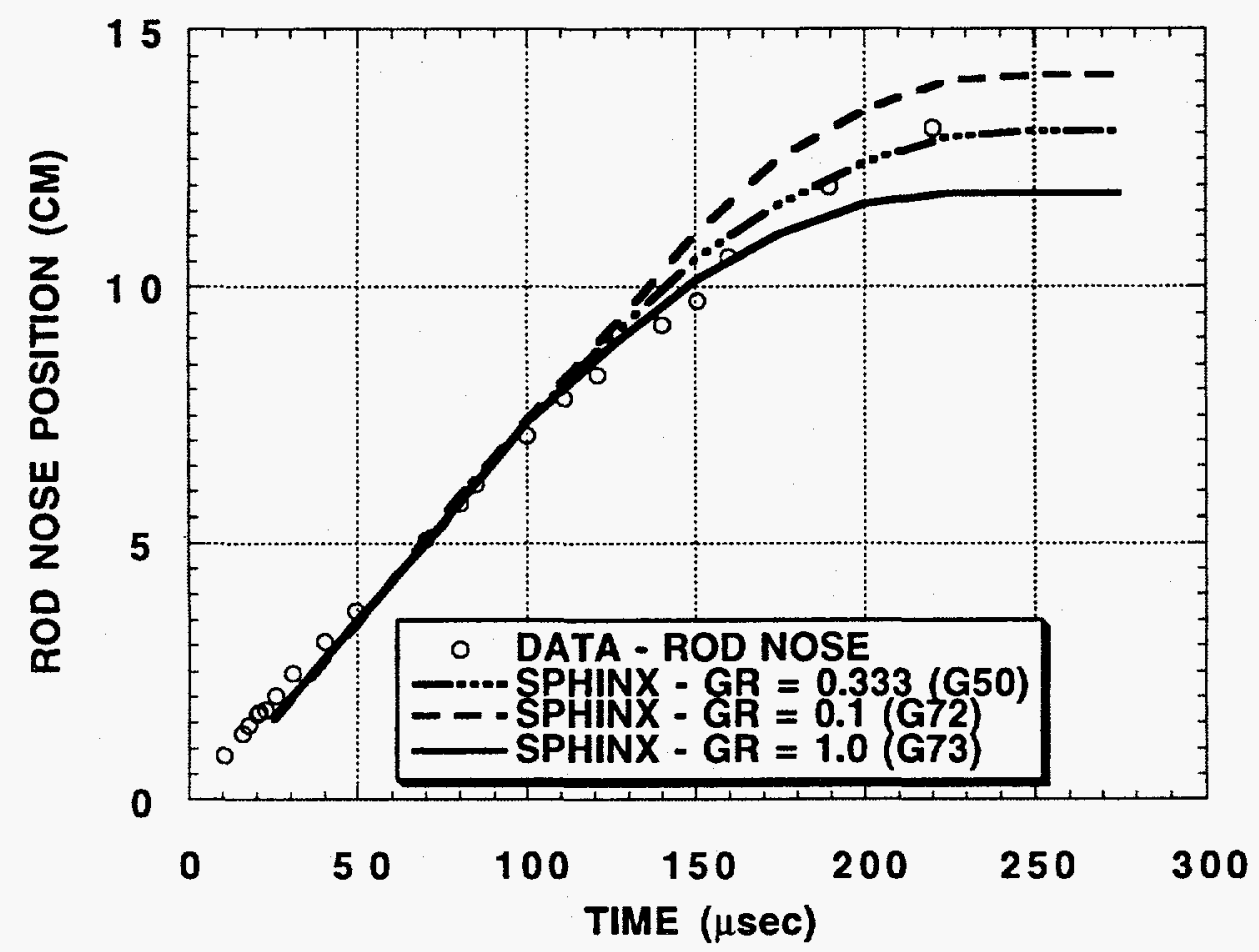

Fig. 14. Predictions of Tungsten Rods Penetrating Glass at $1.25 \mathrm{Km} / \mathrm{Sec}$. Effect of Fractured Glass Shear Modulus.

The predicted results for different fractured glass bulk modulii are shown in Figure 15. The results do not vary smoothly as the value of $K R$ is changed. This effect may be due to the nonlinear interactions between the damage, $\mathrm{KR}$, and the pressure. As damage, $\mathrm{D}$, increases, the bulk modulus changes, resulting in a higher pressure, which results in further damage. In addition, the fractured glass properties are not constants, as used in this work, but functions of the pressure, as well as other variables. 


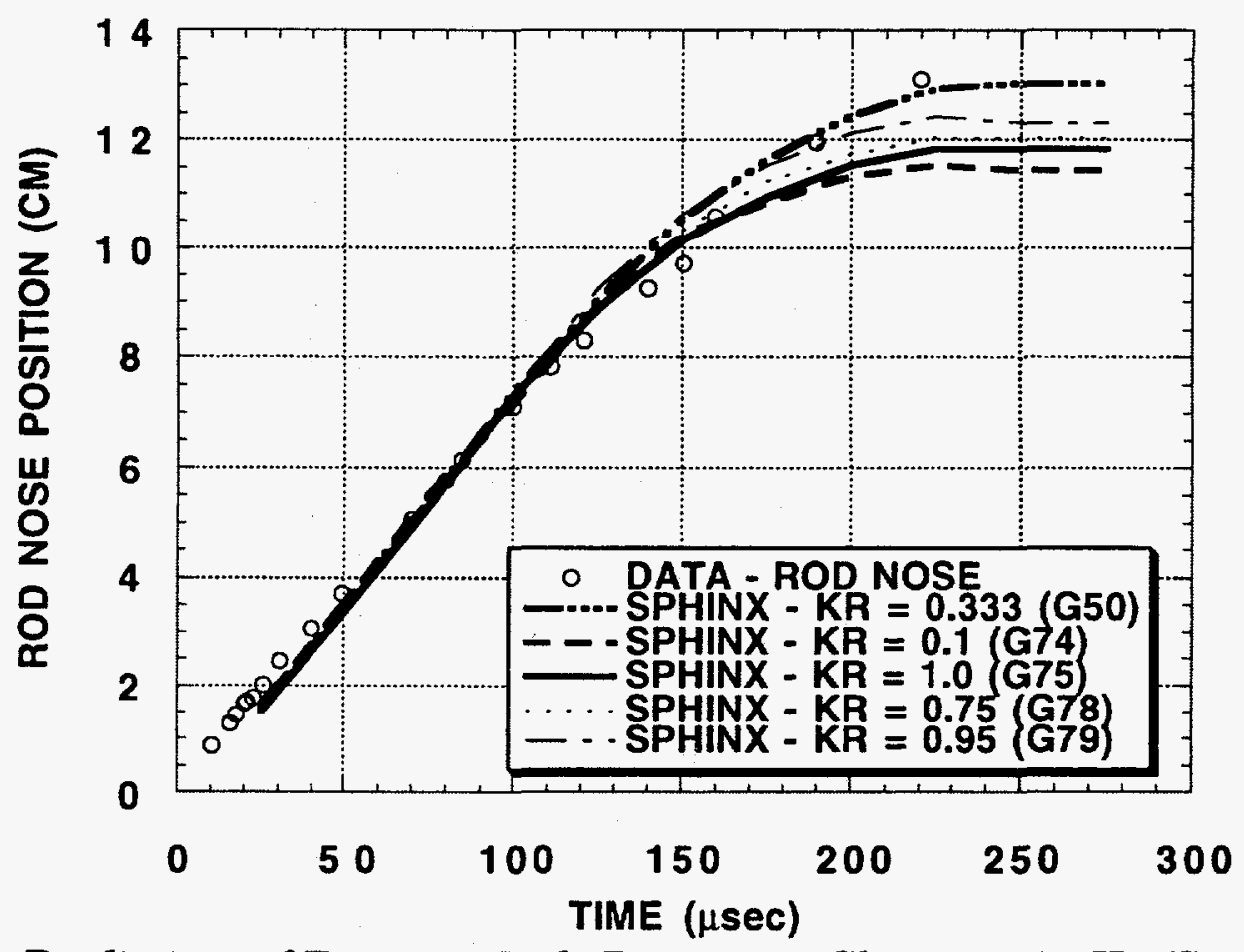

Fig. 15. Predictions of Tungsten Rods Penetating Glass at $1.25 \mathrm{Km} / \mathrm{Sec}$ Effect of Fractured Glass Bulk Modulus.

Figure 16 shows both the rod tip and tail positions for the calculation that best matched the data, for a rod initial velocity of $1.25 \mathrm{~km} / \mathrm{sec}$. As can be seen, the agreement between the predictions and the data is good. 


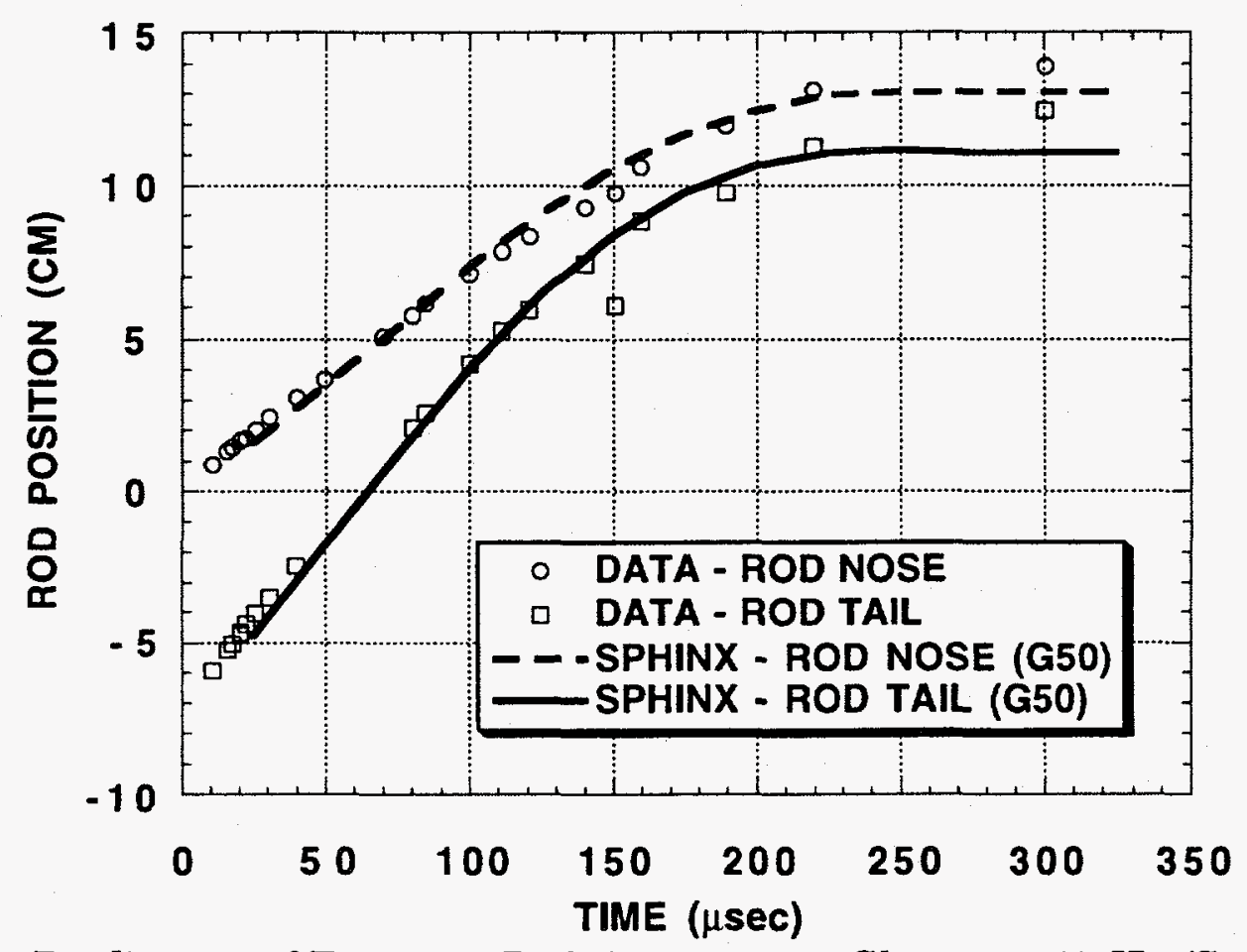

Fig. 16. Predictions of Tungsten Rods Penetrating Glass at $1.25 \mathrm{Km} / \mathrm{Sec}$.

Using the values of the fractured glass properties determined for the experiments in which the rod velocity was $1.25 \mathrm{~km} / \mathrm{sec}$, the experiments in which the rod velocity was $1.70 \mathrm{~km} / \mathrm{sec}$ were predicted. These results are shown in Figure 17. The comparison between the data and the SPHINX predictions is very good. 


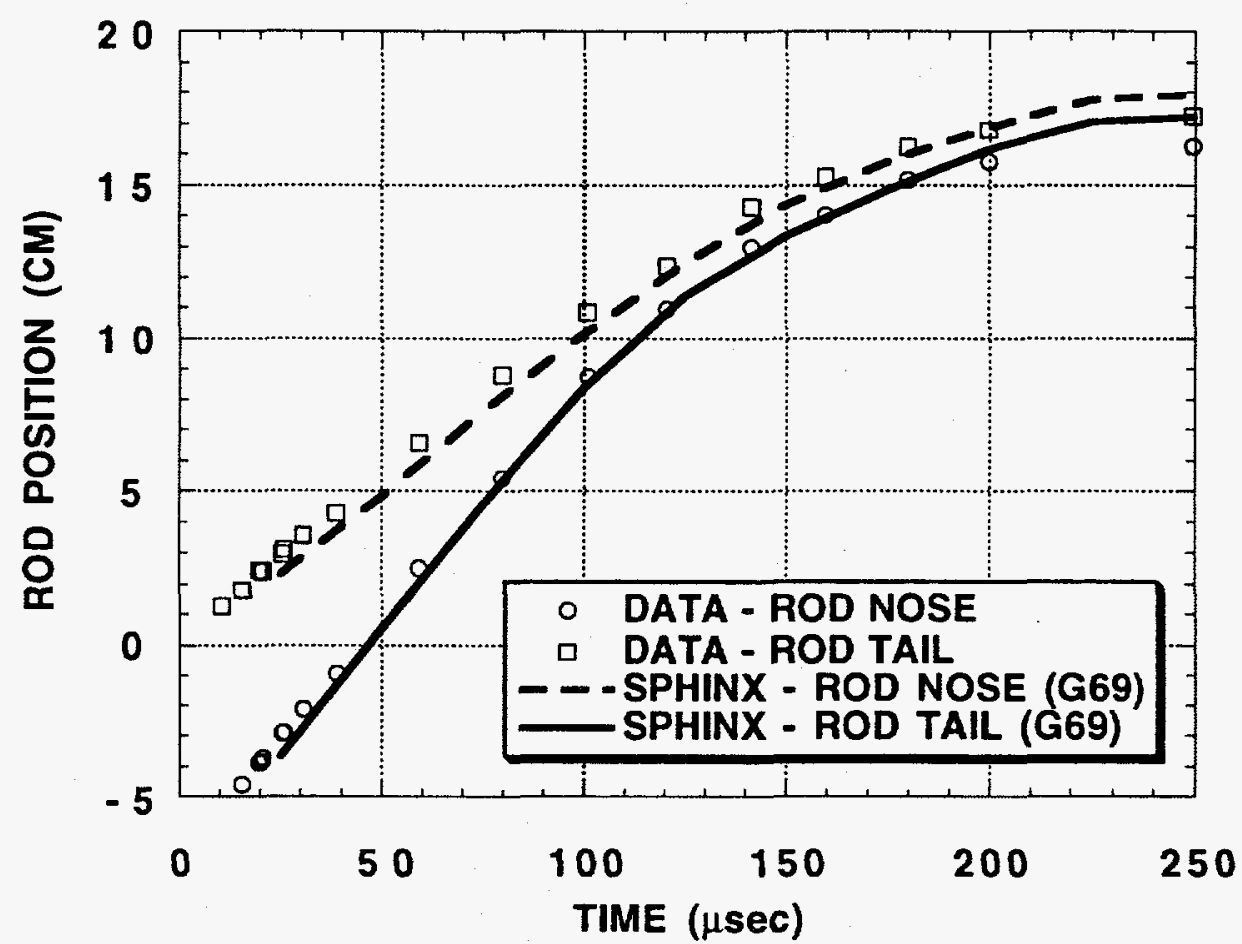

Fig. 17. Predictions of Tungsten Rods Penetrating Glass at $1.7 \mathrm{Km} / \mathrm{Sec}$.

Table 8 shows the Cray Y-MP CPU times required for the calculations using three different numbers of SPH particles. The SPHINX algorithm calculates the number of particles to be used, based on the requested number of particles. Clearly the least number of particles that will result in a converged solution should be used in order to minimize the computer resources required.

\begin{tabular}{|l|l|l|}
\hline RUN NO. & $\begin{array}{l}\text { NO. } \\
\text { PARTICLES } \\
\text { USED }\end{array}$ & $\begin{array}{l}\text { CPU TIME } \\
\text { (MINUTES) }\end{array}$ \\
\hline & & \\
\hline G66 & 804 & 12.0 \\
\hline G71 & 1392 & 33.6 \\
\hline G67 & 2286 & 97.6 \\
\hline
\end{tabular}

Table 8. CPU Times For SPHINX Predictions of Tungsten Rods Penetrating Glass at $1.25 \mathrm{Km} / \mathrm{sec}$.

\section{CONCLUSIONS}

The Cagnoux-Glenn (Cagnoux, 1985; Glenn et al., 1990) glass fracture model has been implemented into the SPHINX smooth particle 
hydrodynamics code. The model has been evaluated by predicting two different types of experiments.

In the first set of experiments, which are one-dimensional, an aluminum flyer plate impacted aluminosilicate glass. The free surface velocities predicted by SPHINX match the data if different spall strengths are used for the higher and lower velocity experiments.

Two-dimensional experiments in which a tungsten rod impacts soda lime (window) glass were also predicted. The results again match the data well, considering that the fractured glass properties are unknown and had to be estimated. The fractured glass properties estimated for one experiment were used in the predictions of the other experiments and the data and predictions agree reasonably well.

Even though the global experimental results predicted by SPHINX, using the Cagnox-Glenn model, are in good agreement with the data, some armor/anti-armor problems and oil well hydrofracturing predictions, require the predictions of more fracture details then can be obtained from the Cagnoux-Glenn model. These problems require the predictions of the actual crack postions and lengths, and in some cases, more exact initial crack times. In order to make these more detailed predictions, we are implementing more advanced brittle fracture models into SPHINX.

\section{ACKNOWLEDGMENT}

This work was supported by the DOE/DoD Munitions Technology Development Program. We would like to thank Dr. L. Schwalbe, Project Leader, and Dr. J. Repa, Program Manager, for their support of this work. We would also like to thank Dr. James D. Walker and Dr. Charles E. Anderson, Jr., Southwest Research Institute, for providing digitized rod tip and tail position data, and for answering a number of questions about their work. 


\section{REFERENCES}

Charles E. Anderson, Jr., Volker Hohler, James D. Walker, and Alois J. Stilp, Penetration of Long Rods into Steel and Glass Targets: Experiments and Computations, Ballistics '93, 14th International Symposium, Quebec, Canada, September 26-29, 1993.

J. Cagnoux, Modele Phenomenlogique D'Ecaillage D'Un Pyrex (Phenomenological Model of Spalling of Pyrex Glass), Journal De Physique, Colloque C5, supplement au no8 Tome 46, 1985.

L. A. Glenn, B. Moran, and A. Kusubov, Modeling Jet Penetration In Glass, Conference on the Application of 3-D Hydrocodes to Armor/Anti-Armor Problems, Ballistic Research Laboratory, Aberdeen Proving Grounds, MD, May 1990.

D. E. Grady and M. E. Kipp, Continuum Modelling of Explosive Fracture in Oil Shale, Int. J. Rock Mech. Min. Sci. \& Geomech. Abstr., Vol. 17, pp 147$157,1980$.

D. E. Grady and J. L. Wise, Dynamic Properties of Ceramic Materials, Sandia National Laboratories Report SAND93-0610, September, 1993.

K. S. Holian, T-4 Handbook of Material Properties Data Bases, Los Alamos National Laboratory Report LA-10160-MS, November, 1984.

G. R. Johnson and W. H. Cook, A Constitutive Model and Data for Metals Subjected to Large Strains, High Strain Rates and High Temperatures, Seventh International Symposium on Ballistics, The Hague, The Netherlands, 1983.

David A. Mandell, Prediction of Alumina Penetration, Los Alamos National Laboratory Report LA-12520, February, 1993.

G. F. Raizer, J. L. Wise, R. J. Clifton, D. E. Grady, and D. E. Cox, Plate Impact Response of Ceramics and Glass, J. Appl. Phys., 75 (8), April 15, 1994.

D. J. Steinberg, S. G. Cochran, and M. W. Guinan, A Constitutive Model for Metals Applicable at High Strain Rates, J. Appl. Phy., 51 (3), pp 1498-1504, 1980).

R. F. Stellingwerf and C. A. Wingate, Impact Modeling With Smooth Particle Hydrodynamics, Int. J. Impact Engng, Vol 14, pp 707-718, 1993.

C. A. Wingate and R. F. Stellingwerf, Los Alamos SPHINX Manual Version 5.7, Los Alamos National Laboratory Report LAUR 93-2476, January 28, 1994. 


\section{APPENDIX A - SPHINX INPUT FOR ONE-DIMENSIONAL FLYER PLATE CALCULATIONS}

cat wg24

\# AL FLYER PLATE IMPACTING GLASS TARGET AT 450 METERS/SEC

\# Titles; problem_title WISE GLASS; run_title WG24

\# Damage; damage TRUE

print_damage_tables TRUE

Damagedtmin 50.0 \# Anything $>1$ turns off damage dt control.

\# Density; continuity TRUE

\# Dumps; restart_time_skip_fraction 0.16666667

history_time_skip_fraction 0.001

\# Exit; max_steps 0;

\# Geometry; cylindrical FALSE; dimension 1

\# Global; step_print_delta 1

\# Graphics; graphics FALSE; plot_xminmax 1 -4. 4.;

\# Particles; nparticles 1000

\# Strength; strength TRUE; disable_melt_cutoff TRUE

\# H; h_vary FALSE; $\quad$ h_inp 1.0

Lagrangian_probe 1.00 .00 .0

dt_mult 0.2

h_inp 1.5

\#\#\#\#\#\#\#\#\#\#\#\#\# FLYER \#\#\#\#\#\#\#\#\#\#\#\#\#\#\#\#\#\#\#\#\#\#\#\#\#\#\#\#\#

\# Set up the projectile

create_object rod

density 2.7128445 ; velocity $0.450 \mathrm{e}+05 \quad 0.0 .0$

type cylinder radius 2.5 length 0.36

strength_material al_6061_t6; strength_model Basic

end_object

eos_material al_6061_t6; $\quad$ eos_model Grueneissen

translate_object rod $-.18 \quad 0.0 .0$

\#\#\#\#\#\#\#\#\#\#\#\#\# Plate \#\#\#\#\#\#\#\#\#\#\#\#\#\#\#\#\#\#\#\#\#\#\#\#\#\#\#\#\#\#\#

\# Set up the plate

create_object plate

density 2.60

type cylinder radius 2.5 length 0.50

strength_material glass; strength_model Basic 


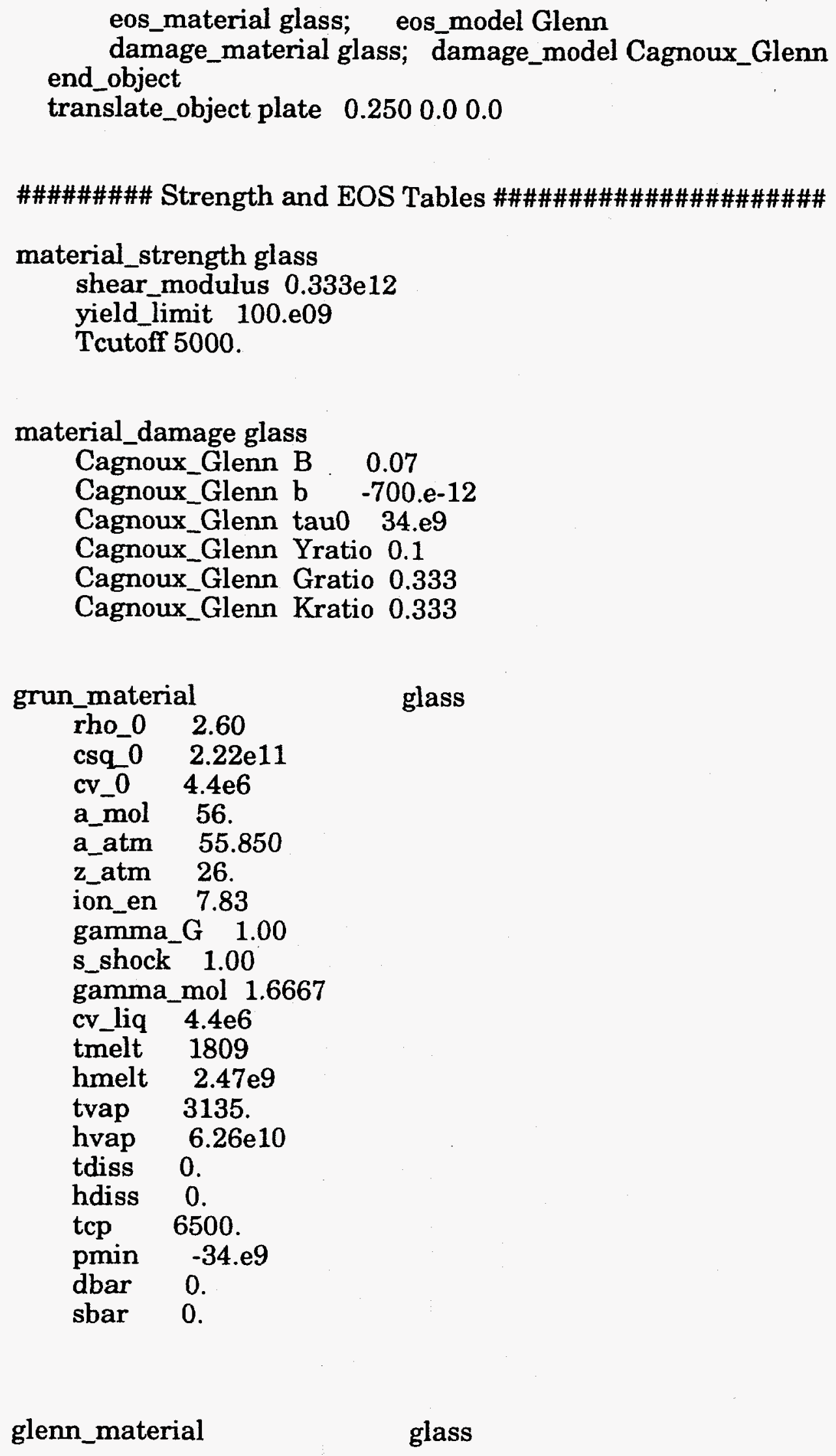
end_object

translate_object plate $\quad 0.250 \quad 0.0 \quad 0.0$

\#\#\#\#\#\#\#\#\# Strength and EOS Tables \#\#\#\#\#\#\#\#\#\#\#\#\#\#\#\#\#\#\#\#

material_strength glass

shear_modulus $0.333 \mathrm{e} 12$

yield_limit 100.e09

Tcutoff 5000 . 
rho_0 2.60

cv_0 $\quad 4.4 \mathrm{e} 6$

pmin $\quad-34 . e 9$

$\mathrm{K} \quad 0.417 \mathrm{e} 12$ 


\section{APPENDIX B - SPHINX INPUT FOR TUNGSTEN RODS IMPACTING STEEL CALCULATIONS}

cat steel04

\# KE ROD IMPACTING ARMOR STEEL

\# Titles; problem_title KE ROD - STEEL; run_title STEEL04

\# Density; continuity TRUE

\# Dumps; restart_time_skip_fraction 0.10

history_time_skip_fraction 0.05

\# Exit; max_steps 0;

max_time 60.e-06

\# Geometry; cylindrical TRUE;

\# Global; step_print_delta 1

\# Graphics; graphics FALSE; plot_xminmax 10.8 .;

\# Particles; nparticles 5000 nparticle_mult 1.0

\# Strength; strength TRUE;

dimension 2 dump strength value
$\# \mathrm{H}$
h_vary TRUE;

\section{西}

disable_melt_cutoff FALSE

particle_plot_cycle_frequency 2

plot_yminmax $2-2.15$.

TRUE; print_
h_inp
0
use_grid_gen TRUE
dt_mult 0.8

disable_av_dt_control TRUE

sph_form 23

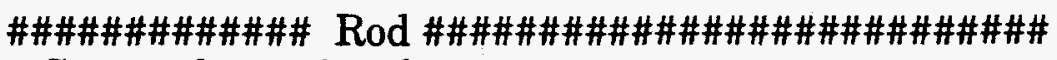

\# Set up the projectile

create_object rod

density 17.75 ; velocity $0.1 .25 \mathrm{e}+050$.

type cylinder radius 0.20 length 5.0

move_to_h rod y 0.5

strength_material W_Libersky; strength_model Basic

material_strength W_Libersky

shear_modulus $1.388 \mathrm{e} 12$

yield_limit 13.0e09

Tcutoff 5000 .

eos_material W1; eos_model sesame

sesame_material_number 3541; sesame_pmin -.02e12

grun_material
rho_0 17.75
csq_0 $\quad 15.94 \mathrm{e} 10$
cv_0 $\quad 1.3 \mathrm{e} 6$
a_mol 184. 


$\begin{array}{ll}\text { a_atm } & 183.85 \\ \text { z_atm } & 74 . \\ \text { ion_en } & 9.18 \\ \text { gamma_G } 1.54 \\ \text { s_shock } & 1.237 \\ \text { gamma_mol } 1.6667 \\ \text { cv_liq } & 1.3 \mathrm{e} 6 \\ \text { tmelt } & 3680 . \\ \text { hmelt } & 0.191 \mathrm{e} 10 \\ \text { tvap } & 5930 . \\ \text { hvap } & 4.35 \mathrm{e} 10 \\ \text { tdiss } & 0 . \\ \text { hdiss } & 0 . \\ \text { tcp } & 15000 . \\ \text { pmin } & -60 . \mathrm{e} 9 \\ \text { dbar } & 2.58961 \mathrm{e} 12 \\ \text { sbar } & \mathbf{3 . 4 2 7 7 3 \mathrm { e } 1 2}\end{array}$

end_object

translate_object rod $0 .-2.5000000 .0$

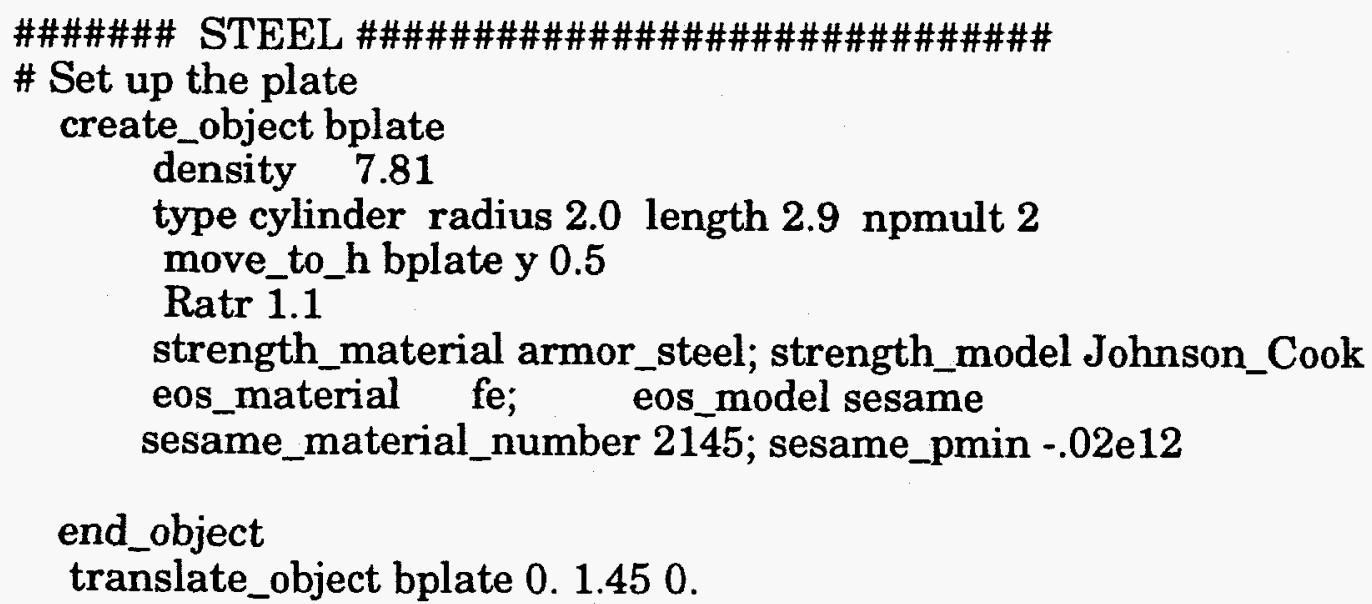




\section{APPENDIX C - SPHINX INPUT FOR TUNGSTEN RODS IMPACTING GLASS CALCULATIONS}

\#debug_eos_glenn TRUE

\#debug_flow TRUE

\#debug_eos TRUE

\# KE ROD IMPACTING GLASS

\# Titles; problem_title KE ROD - GLASS; run_title g50

glass_or $=7.5$

rratio $=1.1$

\# Damage; damage TRUE

print_damage_tables TRUE

Damagedtmin 50.0 \# Anything > 1 turns off damage dt control.

\# Density; continuity TRUE

\# Dumps; restart_time_skip_fraction 0.076923

history_time_skip_fraction 0.05

\# Exit; max_steps 0;

max_time 325.e-06

\# Geometry; cylindrical TRUE;
\# Global; step_print_delta 1

dimension 2

\# Graphics; graphics FALSE; plot_xminmax $1-15.15$; plot_yminmax $1-5 . \overline{2} 5$.

\# Particles; nparticles 5000

nparticle_mult 1.0

use_grid_gen TRUE

dt_mult 0.8

\# Strength; strength TRUE;

disable_melt_cutoff FALSE dump_strength_values FALSE; print_strength_tables TRUE

\# H; h_vary TRUE; $\quad$ h_inp 1.0

\# new energy eq; sph_form 23

\#\#\#\#\#\#\#\#\#\#\#\#\# Rod \#\#\#\#\#\#\#\#\#\#\#\#\#\#\#\#\#\#\#\#\#\#\#\#\#\#\#

\# Set up the projectile

create_object rod

density 17.75 ; velocity $0.1 .25 \mathrm{e}+050$.

type cylinder radius 0.29 length 7.25 npmult 2

\#move_to_h rod y 0.5

strength_material W_Libersky; strength_model Basic eos_material W1; eos_model Grueneissen

end_object

translate_object rod $0 .-4.000000 \quad 0.0$

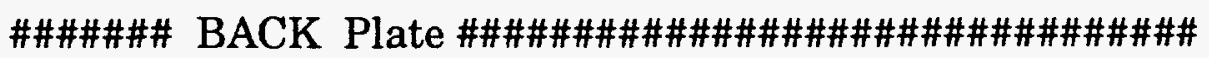

\# Set up the plate 
create_object bplate

density 7.85

type cylinder radius glass_or length 10.0

\#move_to_h bplate y 0.5

Ratr rratio

strength_material mild_steel; strength_model Basic

end_object

eos_material fe; eos_model Grueneissen

translate_object bplate 0.25 .00 .

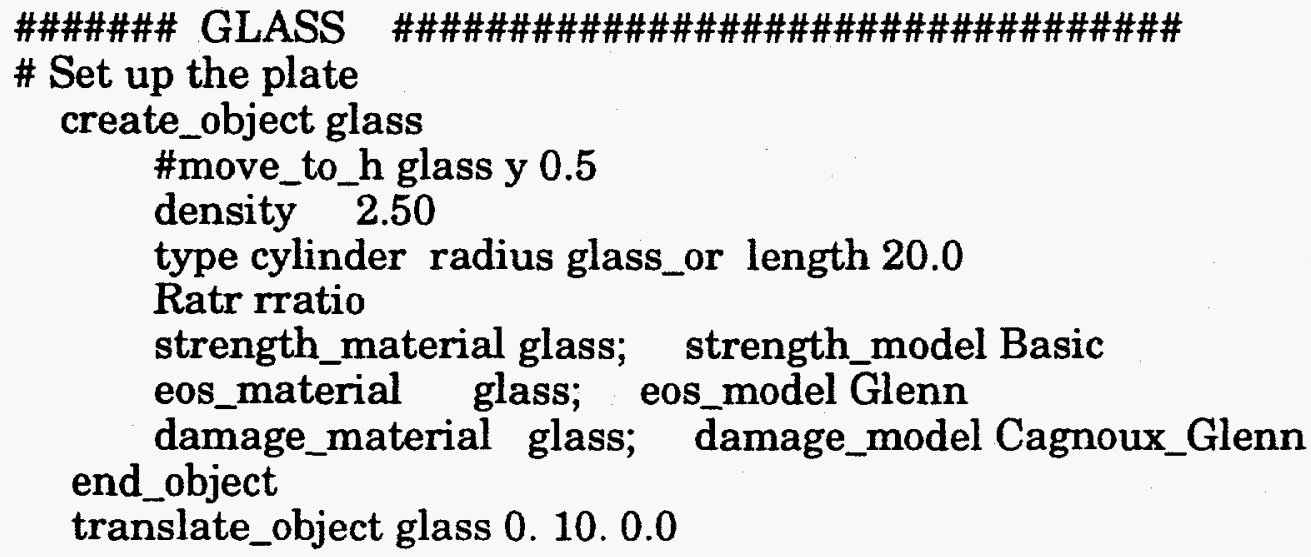

\#\#\#\#\#\#\# GLASS

\# Set up the plate

create_object glass

\#move_to_h glass y 0.5

density 2.50

type cylinder radius glass_or length 20.0

Ratr rratio

strength_material glass; strength_model Basic

eos_material glass; eos_model Glenn

damage_material glass; damage_model Cagnoux_Glenn

end_object

translate_object glass 0.10 .0 .0

\#\#\#\#\#\#\#\#\# Strength and EOS Tables \#\#\#\#\#\#\#\#\#\#\#\#\#\#\#\#\#\#\#\#\#\#\#\#\#

material_strength W_Libersky shear_modulus $1.388 \mathrm{e} 12$

yield_limit $13.0 \mathrm{e} 09$

Tcutoff 5000 .

material_strength glass

shear_modulus $0.333 \mathrm{e} 12$

yield_limit $10 . \mathrm{e} 09$

Tcutoff 5000 .

material_damage glass

Cagnoux_Glenn B $\quad 0.07$

Cagnoux_Glenn b $\quad-700 . e-12$

Cagnoux_Glenn tau0 $0.9 \mathrm{e} 09$

Cagnoux_Glenn Yratio 0.08

Cagnoux_Glenn Gratio 0.333

Cagnoux_Glenn Kratio 0.333

grun_material

W1

rho_0 17.75 


$\begin{array}{ll}\text { csq_0 } & 15.94 \mathrm{e} 10 \\ \text { cv_0 } & 1.3 e 6 \\ \text { a_mol } & 184 . \\ \text { a_atm } & 183.85 \\ \text { z_atm } & 74 . \\ \text { ion_en } & 9.18 \\ \text { gamma_G } 1.54 \\ \text { s_shock } & 1.237 \\ \text { gamma_mol } 1.6667 \\ \text { cv_liq } & 1.3 \mathrm{e} 6 \\ \text { tmelt } & 3680 . \\ \text { hmelt } & 0.191 \mathrm{e} 10 \\ \text { tvap } & 5930 . \\ \text { hvap } & 4.35 \mathrm{e} 10 \\ \text { tdiss } & 0 . \\ \text { hdiss } & 0 . \\ \text { tcp } & 15000 . \\ \text { pmin } & -60 . \mathrm{e} 9 \\ \text { dbar } & 2.58961 \mathrm{e} 12 \\ \text { sbar } & 3.42773 \mathrm{e} 12\end{array}$

$\begin{array}{ll}\text { grun_material } \\ \text { rho_0 } & 2.50 \\ \text { csq_0 } & 2.22 \mathrm{e} 11 \\ \text { cv_0 } & 4.4 \mathrm{e} 6 \\ \text { a_mol } & 56 . \\ \text { a_atm } & 55.850 \\ \text { z_atm } & 26 . \\ \text { ion_en } & 7.83 \\ \text { gamma_G } 1.00 \\ \text { s_shock } & 1.00 \\ \text { gamma_mol } 1.6667 \\ \text { cv_liq } & 4.4 \mathrm{e} 6 \\ \text { tmelt } & 1809 \\ \text { hmelt } & 2.47 \mathrm{e} 9 \\ \text { tvap } & 3135 . \\ \text { hvap } & 6.26 \mathrm{e} 10 \\ \text { tdiss } & 0 . \\ \text { hdiss } & 0 . \\ \text { tcp } & 6500 . \\ \text { pmin } & -0.9 \mathrm{e} 9 \\ \text { dbar } & 0 . \\ \text { sbar } & 0 .\end{array}$


rho_0 2.50

cv_0 $\quad 4.4 \mathrm{e} 6$

pmin $\quad-0.9 \mathrm{e} 9$

$\mathrm{K} \quad 0.555 \mathrm{e} 12$ 